January 2022

\title{
Comparison of Student Outcomes in a Course-based Undergraduate Research Experience: Face-to-Face, Hybrid, and Online Delivery of a Biology Laboratory
}

\author{
Sue Ellen DeChenne-Peters \\ Georgia Southern University, sdechennepeters@georgiasouthern.edu \\ Elizabeth Sargent \\ Georgia Southern University, College of Science and Mathematics, esargent@georgiasouthern.edu \\ Scott C. Mateer \\ Georgia Southern University, smateer@georgiasouthern.edu \\ Marylou Machingura \\ Georgia Southern University, mmachingura@georgiasouthern.edu \\ Jennifer Zettler \\ Georgia Southern University, jzettler@georgiasouthern.edu
}

See next page for additional authors

Follow this and additional works at: https://digitalcommons.georgiasouthern.edu/ij-sotl

\begin{abstract}
Recommended Citation
DeChenne-Peters, Sue Ellen; Sargent, Elizabeth; Mateer, Scott C.; Machingura, Marylou; Zettler, Jennifer; Ness, Traci; DeMars, Geneva; Cannon, Sherri; and BrofttBailey, Jennifer (2022) "Comparison of Student Outcomes in a Course-based Undergraduate Research Experience: Face-to-Face, Hybrid, and Online Delivery of a Biology Laboratory," International Journal for the Scholarship of Teaching and Learning: Vol. 16: No. 1, Article 5.

Available at: https://doi.org/10.20429/ijsotl.2022.160105
\end{abstract}




\title{
Comparison of Student Outcomes in a Course-based Undergraduate Research Experience: Face-to-Face, Hybrid, and Online Delivery of a Biology Laboratory
}

\begin{abstract}
Course-based undergraduate research experiences (CUREs) incorporate authentic research instead of confirmatory exercises into laboratory courses. Following the COVID-19 pandemic, there has been a general shift in instructional modalities from face-to-face (F2F) towards hybrid and online teaching. Student impacts caused by the abrupt shift to online teaching have been characterized, but comparisons between modalities for CUREs are missing. Therefore, we evaluated student learning and attitudinal outcomes in F2F, hybrid, and online delivery of an introductory college biology CURE. Additionally, we compared student outcomes between White/Asian students and persons excluded due to ethnicity or race (PEER) in these modalities. There were significant learning differences between modalities, but there were no significant learning differences by PEER status. Of six attitudinal variables, one varied significantly by modality and three varied significantly for PEER students. These results suggest that CUREs can be adapted to the online or hybrid modality with minimal impacts on student outcomes.
\end{abstract}

\section{Keywords}

biology laboratory, CURE, hybrid, online, science identity, self-efficacy

\section{Creative Commons License}

\section{c)}

This work is licensed under a Creative Commons Attribution-Noncommercial-No Derivative Works 4.0 License.

\section{Cover Page Footnote}

We would like to thank all of the students enrolled in this introductory biology course for allowing us the privilege of using their data for this study. We thank the Bordenstein Lab and the Wolbachia Project at Vanderbilt University for developing the original laboratory course that inspired this work and for continuing to provide Drosophila controls used by our F2F and hybrid modality students. We would also like to thank Sana Omar for her work on data collection and initial characterization of the Fall 2019 F2F modality in this study. This study was approved by the IRB of \{institution 1 \} (H19002). This study was funded by the National Science Foundation (DUE-1245077) and the Biology Department of \{institution 1\}.

\section{Authors}

Sue Ellen DeChenne-Peters, Elizabeth Sargent, Scott C. Mateer, Marylou Machingura, Jennifer Zettler, Traci Ness, Geneva DeMars, Sherri Cannon, and Jennifer BrofttBailey 


\title{
Comparison of Student Outcomes in a Course-based Undergraduate Research Experience: Face-to-Face, Hybrid, and Online Delivery of a Biology Laboratory
}

\author{
Sue Ellen DeChenne-Peters, Elizabeth Sargent, Scott C. Mateer, Marylou Machingura, Jennifer Zettler, \\ Traci Ness, Geneva DeMars, Sherri Cannon, and Jennifer Broftt Bailey \\ Georgia Southern University
}

Received: I5 September 202I; Accepted: 12 November 202 I

\begin{abstract}
Course-based undergraduate research experiences (CUREs) incorporate authentic research instead of confirmatory exercises into laboratory courses. Following the COVID-19 pandemic, there has been a general shift in instructional modalities from face-to-face (F2F) towards hybrid and online teaching. Student impacts caused by the abrupt shift to online teaching have been characterized, but comparisons between modalities for CUREs are missing. Therefore, we evaluated student learning and attitudinal outcomes in F2F, hybrid, and online delivery of an introductory college biology CURE. Additionally, we compared student outcomes between White/Asian students and persons excluded due to ethnicity or race (PEER) in these modalities. There were significant learning differences between modalities, but there were no significant learning differences by PEER status. Of six attitudinal variables, one varied significantly by modality and three varied significantly for PEER students. These results suggest that CUREs can be adapted to the online or hybrid modality with minimal impacts on student outcomes.
\end{abstract}

\section{INTRODUCTION}

The flexibility of online education is an attractive option for a diverse array of students. Well-designed online classes are at least as effective as face-to face (F2F) for student learning in science, technology, engineering, and mathematics (STEM) (Biel and Brame, 2016; Fauloconer and Gruss, 2018; Paul and Jefferson, 2019; Wladis, Conway, and Hachey, 20I5), although online learning may not provide the same opportunities for persistence to a STEM major for persons (students) excluded (from STEM) due to ethnicity or race (PEER) (Chang et al., 20I4; Kuapp, 20I2;Wladis et al., 20I5) Online learning provides opportunities for STEM students whose access to F2F learning is limited, such as non-traditional students with family or work commitments, place-bound students, and military-affiliated students (Faulconer and Gruss, 2018;Wladis et al., 2015). While the popularity of online learning has drastically increased since the early 2000 s, access to and engagement with practical online laboratory courses has not expanded at the same rate as online lecture (Faulconer and Gruss, 20 I8; Waldrop, 20I3). One major concern is the inability of online students to access laboratory equipment (Biel and Brame, 2016; Faulconer and Gruss, 2018). Undergraduate science courses typically include an experimental laboratory component, allowing students to gain hands-on experience with scientific techniques. F2F laboratories can come with a high financial burden due to the cost of laboratory equipment, consumables, technology, and instruction, which can limit accessibility for students who need these courses (Son, Narguizian, Beltz, and Desharnais, 2016;Wladis et al., 2015). Research with online laboratory courses is limited (Biel and Brame, 2016; Faulconer and Gruss, 2018). However, when the COVID-I 9 pandemic universally forced education online in the spring and summer of 2020 , it changed the demographics of the online student population. This provided an opportunity for increased STEM laboratory distance learning course options and assessment (Babinčáková and Bernard, 2020; Sommers et al., 2021).

\section{Laboratory Modalities}

F2F laboratory experiences typically involve a lecture component followed by hands-on experience in dedicated classrooms (called laboratory classes/exercises in this manuscript). They are characterized by physical interaction with laboratory equipment, $\mathrm{F} 2 \mathrm{~F}$ interactions between students in small groups, as well as F2F interactions between students and an instructor (Rivera, 2016). Online laboratory classes, however, exhibit a remarkable diversity including: completely virtual simulations, hands-on laboratories completed at a distance from the campus, and accessing real instruments and data through a computer (Falconer and Gruss, 2018). For this study, we define online laboratories as usually asynchronous, self-paced learning environments in which the instructor guides the pedagogy in the virtual environment, but which lack F2F interaction with laboratory equipment, other students, and the instructor. Arguably, compared to online laboratory courses, the F2F experience provides students with better facilities, laboratory equipment, and development of advanced technical skills (Fogg, Carlson-Sabelli, Carlson, and Giddens, 2013; Faulconer and Gruss; 20I8; Mawn, Carrico, Charuk, Stote, and Lawrence, 20I I). However, even without the direct use of laboratory equipment, most research indicates online laboratories provide comparable or increased learning (Biel and Brame, 2016; Kuyatt and Baker, 20 I4; Mawn et al., 20 I I;Al Musawi, Ambusaidi, Al-Balushi, S., and Al-Balushi, K., 20I 5; Potkonjak, Jovanovic, Holland, and Uhomoibhi, 20I3; Zeynep and Alipasa, 20I3) and higher course satisfaction than F2F laboratories (Brockman et al., 2020; Mgutshini, 20I3). Research in online laboratories has not considered student attitudinal variables, rarely compares the exact same laboratory courses in each modality, and is still limited to a few studies (Faulconer and Gruss, 2018).

A third modality of laboratory instruction, hybrid classrooms, is characterized by $\mathrm{F} 2 \mathrm{~F}$ instruction that is complemented by remote online activities that replace some in-person sessions. These classrooms merge the flexibility and accessibility of an online classroom with the tactile experience of F2F instruction, and are collectively recognized as an effective instruction method 
(McCowan 2010; Son et al., 2016). Hybrid laboratory courses also alleviate some of the expenses associated with full F2F course delivery, but the cost per student still exceeds that of fully online courses (Son et al., 2016). When carefully designed to take advantage of the virtual environment, student outcomes in learning and attitudes towards science are best in the hybrid modality compared to fully online instruction or F2F activities alone (Olympiou and Zacharia, 20I2; Son et al., 20I6). This blending of accessibility with practical experiences provides students the best of both worlds and is potentially the wave of the future (Trpkovska, 20I I). While these studies are encouraging, there is a paucity of research on hybrid laboratory experiences.

\section{CURES}

Undergraduate research experiences increase student success. These experiences benefit students in their understanding of and confidence in STEM, their persistence to degree, as well as increase their interest in pursuing STEM careers (National Academies of Sciences and Medicine, 20 I7; Russell, Hancock, and McCullough, 2007; Sadler and McKinney, 20 I0; Spell, Guinan, Miller, and Beck, 2014). However, these individually mentored research experiences can come with a high resource cost (e.g., faculty time, space, money) (Bangera and Brownell, 20I4; Wei and Wooden, 20I I). CUREs move research into the classroom, making undergraduate research accessible to more students while simultaneously reducing resource costs compared to individual student research projects (Bangera and Brownell, 2014; Barral, Makhluf, Soneral, and Gasper, 2014; Olimpo, DeChenne-Peters, Fisher, 20I6; Russell et al., 20 I5; Shaffer et al., 2010; Wei and Wooden, 20I I) CUREs include projects that have scientific relevance, discovery of new scientific information, and integrate students in scientific processes (Corwin, Graham, and Dolan, 2015). CUREs have been implemented in all levels of science courses and with small to very large enrollments (Brownell et al., 20I5; Corwin et al., 20I5; Genet 202I; Olimpo et al., 2016). In comparison, traditional laboratories generally include confirmatory laboratory exercises in which the instructor knows the outcome and students can find the expected outcome. Some traditional laboratories include laboratory exercises where the student is classifying an unknown (to them) compound, chemical, or molecule. Traditional laboratories do not include discovery of new knowledge (Ballen et al., 2017; DeChenne, Carew, and Stains, 20I4). Compared to traditional laboratory courses, CUREs can increase student science learning, persistence in science, and attitudinal measures including: science identity, self-efficacy, project ownership, scientific networking, and science community values (Corwin et al., 20I5, Gin, Rowland, Steinwand, Bruno, and Corwin, 2018; Hanauer et al., 2017; Lapatto 2007; Russell et al., 2015).

There is extremely limited data on student outcomes in online or hybrid CUREs, and all but one study are directly related to COVID-19 mitigation strategies. When transitioning a F2F CURE to online in Spring 2020, Doctor, Lehman, and Korte (202I) found no difference in student exam scores between prior F2F students and those transitioned online. Sommers et al. (202I) compared students who started the semester in a CURE to those in a traditional laboratory, both of which were disrupted and transitioned to complete the semester online. Students that began in the CURE developed a research project, but were not able to conduct it and finished the semester doing the same online laboratories as the traditional laboratory section. Students in the CURE were more likely to think like a scientist compared to the students in the traditional section (Sommers et al., 2020I). In the first comparison of a CURE in online and F2F conditions, Genet (202I) found no differences in students' beliefs towards science or self-reported learning gains between the modalities. However, Genet did not explore the hybrid modality or attitudinal outcomes. Additionally, Genet used student self-reported learning outcomes which can be problematic since students tend to overestimate their own learning (Boud and Falchikov, 1989; Falchidov and Boud, 1989).

\section{PEER status}

To meet the needs of the 2 I st century, we need to have a strong and diverse workforce. However, systemic and pervasive social systems in the United States (US) continue to disproportionately affect nonwhite student groups in STEM at a higher level (Asai, 2020). Generally, students in these groups have been termed "under-represented minorities", reflecting their lower representation in STEM compared to the overall US population. However, this term does not acknowledge systemic systems in US education that continue to deter PEER students from persisting in STEM majors, despite their over-representation among entering university students intending to pursue a STEM degree (Asia, 2020). The term PEER acknowledges this systemic problem and places the onus of change on the system rather than the individual student.

PEER students have lower persistence in STEM than White/ Asian students, especially in online courses (Chang et al., 20l4; Kuapp, 2012;Wladis et al., 2015). A key experience for improving PEER student persistence is undergraduate research (Chang et al., 20I4; Espinosa, 20I I; Russell et al., 2007). While CUREs improve persistence, course performance, and attitudinal outcomes (Corwin et al., 20 15; Hanauer et al., 2017; National Academies of Science, Engineering, and Medicine, 2017; Olimpo et al., 2016; Martin, Rechs, and Landerholdm, 202I), there are few studies that examine CURE impacts on PEER student outcomes. These studies generally show similar or better gains for PEER students compared to their White/Asian classmates (Hanauer et al., 20I7; Ing, Burnette, Azzam, and Wessler, 2020; Kirkpatrick, Schuchardt, Baltz, and Cotner, 2019; Rodenbusch et al., 2016). However, the impact of CUREs on diverse groups of students is not well elucidated, nor has the impact of online CUREs for PEER students been explored.

The main goal of this study was to compare the outcomes of three delivery modalities of the same biology CURE curriculum with respect to student learning and attitudes. Given the limited research on laboratory and even more limited CURE comparisons between F2F, hybrid, and online courses, this study fills a unique need. To our knowledge, this is the first study to compare student outcomes, especially student attitudinal outcomes, for the same CURE taught in F2F, hybrid, and online modalities. Additionally, this study is the first to disaggregate student outcomes by PEER status in these modalities. Our specific research question is: how do student outcomes differ when taught in a F2F, hybrid, or online environment for the same biology CURE?

\section{METHODS \\ Participants}

Students were recruited from introductory cellular and molecular biology laboratory course at Georgia Southern University. This course is required for health-oriented and science majors, 
has no prerequisites, fulfills a science requirement for non-STEM majors, and is the first course in the introductory biology majors' series. At the beginning of each semester, approximately $10 \%$ of the students were under the age of 18 and, therefore, were not included in this study. In total, 254 students in F2F (Fall 2019), 147 from hybrid (Fall 2020) and 55 in online (Spring and Summer 202I) CURE sections participated in this study, completed both tests, and selected the correct response to an item designed to determine if they were reading the survey. This item appears in a list of Likert statements and asks them to select disagree. If they did not select disagree, their survey was removed from the dataset.

Georgia Southern University is a research intensive, regional university in the southeastern US. It is comprised of a four campus system that spans rural, urban, online, and a campus just outside of a major US military base (military-adjacent). This study was comprised of students from the urban, online, and military-adjacent campuses (Table I). The urban and military-adjacent campuses had been a separate university that was consolidated with another university in a rural region after this study was started. The online students included students from all three physical campuses. Reflecting a growing trend in US biology and health-oriented fields, the course was predominantly female (Digest of Education Statistics, 2019). Students in the study were representative of the diverse student population of Georgia Southern University (Table I). However, they do not represent the current diversity of the local area which is $53 \%$ African American and 35\% White (US Census Data, 2020). Based on prior research on student success in STEM (Chang et al., 20I4; Kuapp, 20I2; Wladis et al., 20I5),

\begin{tabular}{|c|c|c|c|}
\hline \multicolumn{4}{|l|}{ Table I. Student Demographics } \\
\hline & $\mathbf{F}^{2} \mathrm{~F}^{\prime}$ & Hybrid $^{2}$ & Online $^{3}$ \\
\hline \multicolumn{4}{|l|}{ Level } \\
\hline Freshman & $58.3 \%$ & $61.9 \%$ & $14.5 \%$ \\
\hline Sophomore & $23.6 \%$ & $23.1 \%$ & $30.9 \%$ \\
\hline Upper-division and post-bac & $18.1 \%$ & $14.9 \%$ & $54.6 \%$ \\
\hline \multicolumn{4}{|l|}{ Ethnicity } \\
\hline African American ${ }^{4}$ & $23.2 \%$ & $26.7 \%$ & $29.1 \%$ \\
\hline Asian American ${ }^{5}$ & $3.5 \%$ & $2.1 \%$ & $1.8 \%$ \\
\hline Hispanic/Latin $x^{4}$ & $7.1 \%$ & $9.6 \%$ & $3.6 \%$ \\
\hline Multi-ethnic ${ }^{4}$ & $3.9 \%$ & $4.8 \%$ & $1.8 \%$ \\
\hline Native American/Pacific Islander ${ }^{4}$ & $0.8 \%$ & $0.7 \%$ & $0 \%$ \\
\hline White $^{5}$ & $56.7 \%$ & $53.4 \%$ & $58.4 \%$ \\
\hline Other/Prefer Not to Answer & $4.3 \%$ & $2.8 \%$ & $5.5 \%$ \\
\hline \multicolumn{4}{|l|}{ Major } \\
\hline Biology & $24.4 \%$ & $20.4 \%$ & $7.3 \%$ \\
\hline Allied Health & $50.0 \%$ & $59.2 \%$ & $61.8 \%$ \\
\hline Other Science & $10.6 \%$ & $7.5 \%$ & $14.5 \%$ \\
\hline Non-Science & $15.0 \%$ & $12.9 \%$ & $16.4 \%$ \\
\hline \multicolumn{4}{|l|}{ Gender } \\
\hline Female & $81.1 \%$ & $78.2 \%$ & $85.5 \%$ \\
\hline Male & $18.1 \%$ & $20.4 \%$ & $12.7 \%$ \\
\hline Prefer Not to Answer & $0.8 \%$ & $1.4 \%$ & $1.8 \%$ \\
\hline First-generation & $15.8 \%$ & $17.8 \%$ & $21.8 \%$ \\
\hline Veteran/Active Duty Military & $6.3 \%$ & $8.9 \%$ & $3.6 \%$ \\
\hline \multicolumn{4}{|c|}{ 'N=254, ${ }^{2} \mathrm{~N}=147,{ }^{3} \mathrm{~N}=55,{ }^{4} \mathrm{PEER},{ }^{5}$ Non-PEER } \\
\hline
\end{tabular}

students were grouped for analysis into those who identified as PEER or White/Asian (Table I).

\section{CURE course description}

The Wolbachia Project was a curriculum originally designed as a laboratory course focusing on real-world integration of research and an introduction to microbiology, molecular biology, and biotechnology techniques for secondary (high school) students (Bordenstein, 2007). The project has been running as a citizen science initiative for over 15 years and has expanded to include multiple formats of delivery in secondary and post-secondary classrooms, but generally involves some or all of the following in each modality: insect collection and identification, literature review, DNA extraction, PCR, gel electrophoresis, and bioinformatics (Lemon, Bordenstein, and Bordenstein, 2020).

The Wolbachia Project was adapted by faculty to an introductory, university-level cell and molecular biology laboratory course in the three discussed modalities over the last 10 years: F2F (prior to COVID-19), hybrid (Fall 2020), and online (one section Spring 2021 and three sections Summer 202I). The hybrid and online formats were designed after the Spring 2020 semester (post COVID-19), and online delivery continues even as most students returned to the F2F classroom. In the F2F modality, students met for three hours each week for 15 weeks to complete their research projects. Students collected and identified their insects, reviewed scientific literature to develop a prediction about the presence of Wolbachia in their insect, analyzed their own insects (DNA isolation, PCR, gel electrophoresis, and bioinformatics) and completed an in-person, final oral presentation of their results. In the hybrid modality, students completed 12 weeks of the project remotely. Students collected and identified their own insects at home, but were present $\mathrm{F} 2 \mathrm{~F}$ in the laboratory classroom to undergo initial equipment training and to perform the following analyses on their insects: DNA extraction, gel electrophoresis and data interpretation. In the online modality, students completed the entire project from home. Students collected and identified their own insects, but the DNA extraction, PCR, and gel electrophoresis were performed by the instructor using a separate insect of matched taxonomic Order. Students analyzed the data the same way in all three modalities. However, in both the hybrid and online modalities, final research presentations were independently recorded and submitted remotely. As adapted by the faculty at Georgia Southern University, this Wolbachia laboratory can be defined as a CURE, as it includes discovery, relevance, and science process skills.

\section{Instruments}

Student learning was measured with 13 questions on scientific content (knowledge) and seven questions which asked students to analyze scientific data related to course content (analysis). This assessment was developed iteratively by biology faculty who teach the course using feedback from student results as well as a biology education expert. The current version of this assessment has been in use since Spring 2019 (see Appendix). Attitudinal variables were collected using the Persistence In The Sciences (PITS) survey (Hanauer, Graham, and Hatfull, 2016). This instrument has been validated with university science students and reliability with this population of students was measured with Cronbach's alpha. The PITS scales ranged from four to 10 items and were reliable (self-efficacy (pretest $\alpha=0.899$, posttest $\alpha=0.929$ ), science iden- 
tity (pretest $\alpha=0.853$, posttest $\alpha=0.887$ ), project ownership (content $\alpha=0.868$, emotion $\alpha=0.903)$, networking $(\alpha=0.810)$, and science community values (pretest $\alpha=0.876$, posttest $\alpha=$ $0.886)$ ). Demographic variables were also collected in the survey.

\section{DATA COLLECTION}

Students were recruited for this study during the first laboratory of the semester.The surveys were administered through Qualtrics during the first laboratory class (pretest) and again during the $14^{\text {th }}$ week of the semester (posttest). In the F2F modality (Fall 20I9), the knowledge and analysis questions constituted part of the final practical exam in the course. In the hybrid and online modalities (Fall 2020 - Summer 2021), practical exams were not given in this course. Instead, the posttest (including knowledge and analysis questions) was given as an assignment which was graded on complete/not complete basis.

\section{ANALYSIS}

For all three instructional modalities, scores for items in analysis, content, and each attitudinal variable were averaged only if all items related to that variable were completed by the student. If there was missing information in a variable it was removed from the analysis for that variable, resulting in slight variation in sample size between variables. To determine changes in learning, the normalized gain (NG, Hake, 1998) for each assessment (knowledge and analysis) was determined with the following formula:

\section{NG $=$ (Percentage posttest score - Percentage pretest score)/(100 - Percentage pretest score)}

NGs allow the comparison of the amount of learning gains for all students independent of their starting point since it sets learning gains compared to the amount the individual student can gain based on their pretest score (Hake, 1998). To compare the effects of teaching modality on student demographics, ANOVAs were used on the NGs. Attitudinal variables (science identity, self-efficacy, and science community values) that measured pre- and posttest differences between modalities (F2F, hybrid, online) and student demographics (PEER, White/Asian) were analyzed using ANCOVAs. Attitudinal variables that were posttest only (project ownership content, project ownership emotion, and networking) were analyzed with ANOVAs. LSD post-hoc tests were used in all analyses where results were significant $(p<0.05)$. The differences in sample size from each modality could result in unequal variances violating ANOVA and ANCOVA assumptions (Rusticus and Lovato, 20I4). Therefore a Levene's test for equality of variance was conducted for each ANOVA and ANCOVA in the study. These indicated that there was not a significant difference in variances between the modalities for each variable ( $p$ ranged from 0.121 to 0.956 ).

\section{RESULTS}

\section{Learning Outcomes}

ANOVAs which included PEER status, modality, and the interaction between PEER status and modality for normalized gains were

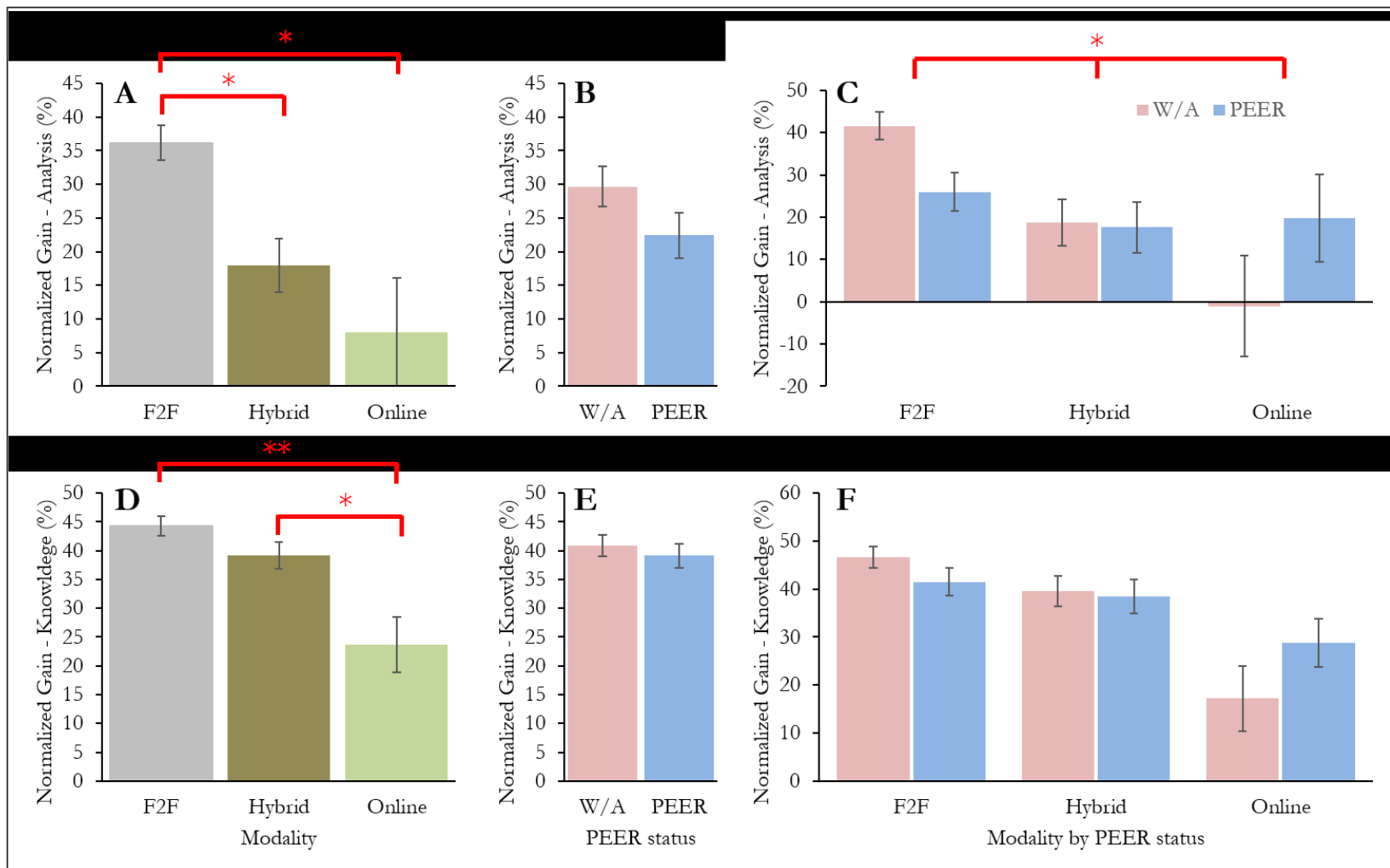

Figure I. Normalized gains in analysis and knowledge. No overall difference between PEER and White/Asian students was detected for analysis or knowledge gains $(B, E)$. F2F students $(n=238)$ significantly outperformed hybrid $(p=0.002, n=I 30)$ and online students $(p=0.00 \mathrm{I}, \mathrm{n}=49)$ in analytical gains (red bars, panel $\mathrm{A}$ ). For analysis, there was a significant interaction between PEER status and modality where PEER students performed worse in the F2F modality, the same in the hybrid modality, and better in the online modality than their White/Asian peers $(p=0.033$, red bar, panel $C)$. Online students $(n=47)$ scored significantly lower than students in the F2F $(p<0.00 \mathrm{I}, \mathrm{n}=228)$ and hybrid modalities $(p=0.00 \mathrm{I}, \mathrm{n}=126)$ in knowledge gains (red bars, panel $\mathrm{D})$. No significant interaction occurred between PEER status and modality for knowledge gains (panel F). Error bars represent standard error. Statistically significant differences between modalities are indicated with red bars with * indicating $p<0.05$ and ** indicating $p<0.00 \mathrm{I}$. 
significant (Figure I, analysis $F(416,5)=6.60 I, p<0.00 I$; knowledge $F(405,5)=6.680, p<0.00 I)$. For the analysis questions, students in the F2F scored higher than the hybrid $(p=0.002)$ or online students $(p=0.00 \mathrm{I})$ (Figure IA). While there was no significant difference between PEER and White/Asian students normalized analysis gains (Figure IB), there was a significant interaction between PEER status and modality (Figure IC, $p=0.033$ ). As can be seen in Figure IC, the pattern of normalized gains for the analysis question is different for PEER andWhite/Asian students in each modality. For the analysis questions, PEER students performed worse in the F2F modality, similarly in the hybrid modality, and better in the online modality than their White/Asian peers. For the knowledge questions, students in the online modality scored lower than students in the F2F $(p<0.00 \mathrm{I})$ and hybrid modalities $(p=0.00 \mathrm{I})$ (Figure ID). As with analysis, there was no significant difference in normalized knowledge gains between PEER and White/Asian students (Figure IE). However, unlike the analysis questions, there was no significant interaction between PEER status and modality indicating no difference by PEER status within modality (Figure IF).

\section{Attitudinal Outcomes}

ANOVAs which included PEER status, modality, and an interaction between PEER status and modality indicated that there were no significant differences in modality, PEER status, or interactions between modality and PEER status for project ownership (Figure $2 A \& 2 B$, content $F(435,5)=1.706, p=0.132, M=3.76$ $S E=0.030$; Figure $2 C$ and $2 D$, emotion $(F(435,4)=1.402, p=0.222$, $M=3.510, S E=0.037)$. However, the networking ANOVA was significant (Figure 2E and 2F, $F(435,5)=3.616, p=0.003$ ). Students in the online modality have significantly lower networking than those in the F2F or hybrid modalities (Figure 2E, $F=7.165, p=0.002$ ). PEER students also have lower networking than White/Asian students (Figure 2F, $F=6.164, p=0.008$ ). There was no significant effect for the interaction between PEER status and modality indicating no difference by PEER status within modality.

ANCOVAs which included PEER status, modality, and an interaction between PEER status and modality as well as pretest as a covariate were significant (Figure 3 , science identity $(F(430$, $6)=33.3 \mathrm{I} 3, p<0.00 \mathrm{I}$; Figure 4, self-efficacy $(F(429,6)=6.534$, $p<0.00 \mathrm{I}$; Figure 5 , science community values $(F(428,6)=35.340$, $p<0.00 \mathrm{I})$. For science identity the only significant difference was the improvement from pretest to posttest (Figure 3C, $F=195.313$, $p<0.00 \mathrm{I}$ ) indicating improvement for students in all modalities (Figure $3 \mathrm{~A}$ ) and by PEER status (Figure $3 \mathrm{~B}$ ) was equivalent. For self-efficacy, the students also improved from pretest to posttest (Figure 4C, $F=76.275, p<0.00 \mathrm{I}$ ) and there was no difference in that improvement between modalities (Figure 4A). However, PEER

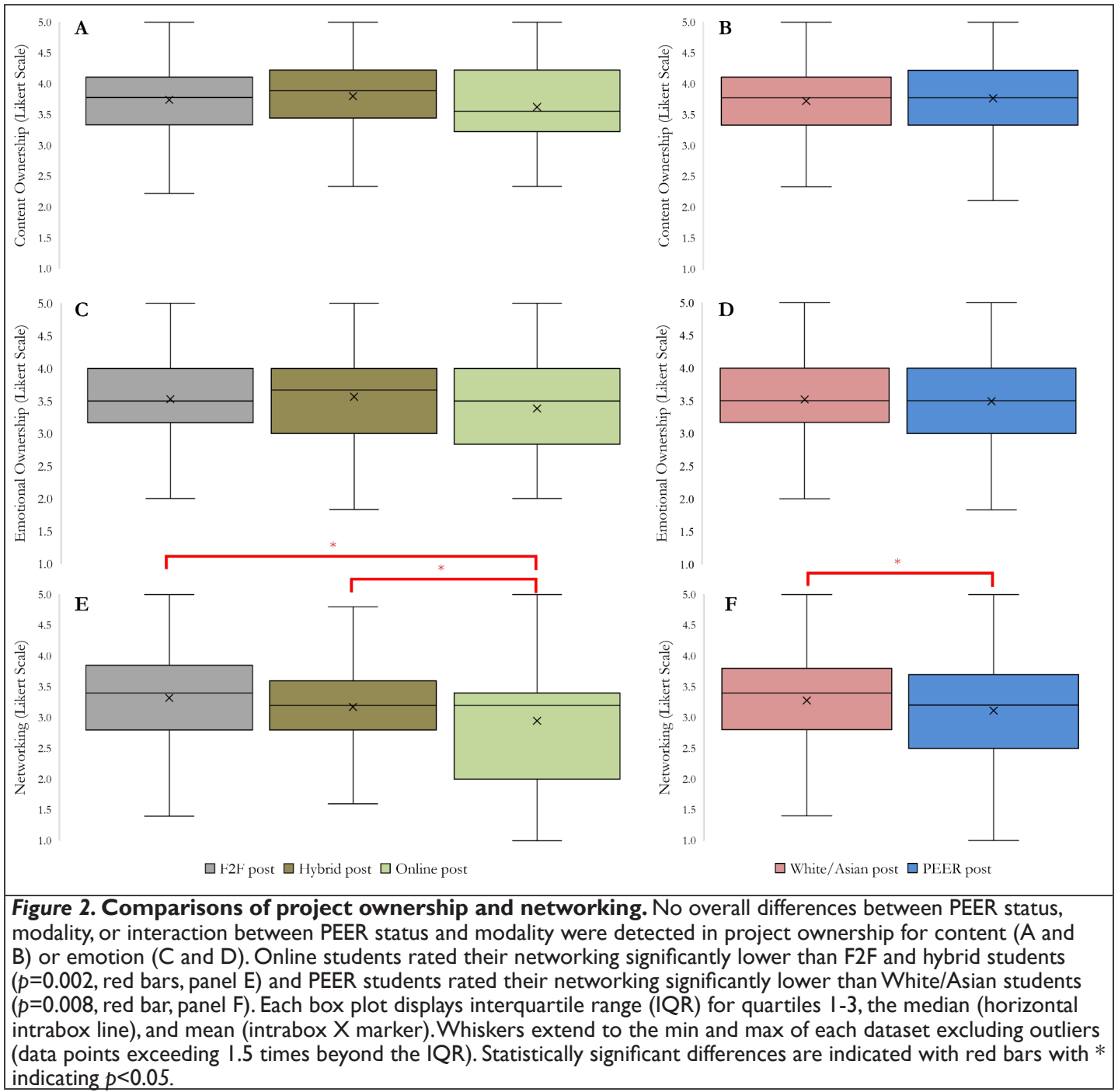


students had significantly less improvement than their White/ Asian peers (Figure 4B, $F=9.452, p=0.002$ ). For science community values, there was a small but significant increase from pretest to posttest (Figure $5 C, F=186.815, p<0.00 I$ ) as well as no difference between modalities (Figure 5A, $F=1.707, p=0.183$ ). Additionally, PEER students had significantly lower science community values (Figure 5B, $F=7.036, p=0.008$ ) than their White/Asian peers. In fact, the science community values for PEER students dropped while White/Asian student science community values increased.

\section{DISCUSSION}

The COVID-I9 pandemic required that instructional modalities shift from F2F towards hybrid and online teaching, which presented a unique opportunity to quantitatively compare the student impacts these changes present for CURE courses. Learning outcomes show significant differences for students in the F2F, hybrid, and online laboratory modalities, but there were no significant differences between White/Asian and PEER students. However, there was a significant interaction between modality and PEER status for the analysis questions. Out of six attitudinal outcomes, only one (networking) indicated a significant difference between modalities. However, for three of the attitudinal outcomes (networking, self-efficacy, and science community values), PEER students' responses were significantly lower than White/Asian students' regardless of modality. These are encouraging results for expanding access to CUREs to the hybrid and online environment.

\section{LIMITATIONS}

These results require careful interpretation as differences in student composition and possible motivational differences between modalities may have contributed to the results presented here. More upper-division students and fewer biology majors were in the summer online cohort when compared to sections offered during the normal academic year (Table I). However, this is a pattern consistent with previous enrollment data for our institution. In the Spring 202I semester, students had the option of enrolling in F2F or online sections of the CURE, giving rise to a possible selection bias of students for online learning that semester (Brownell, Kloser, Fukami, and Shavelson, 20I3). Since most of the students in the online cohort were from the summer session where no F2F option was available, the impacts from any selection bias would be reduced. Differences in grading of the knowledge and analysis questions for the F2F, hybrid, and online students may have impacted student motivation on the posttest. Students in the F2F modality were given four practical exams throughout the

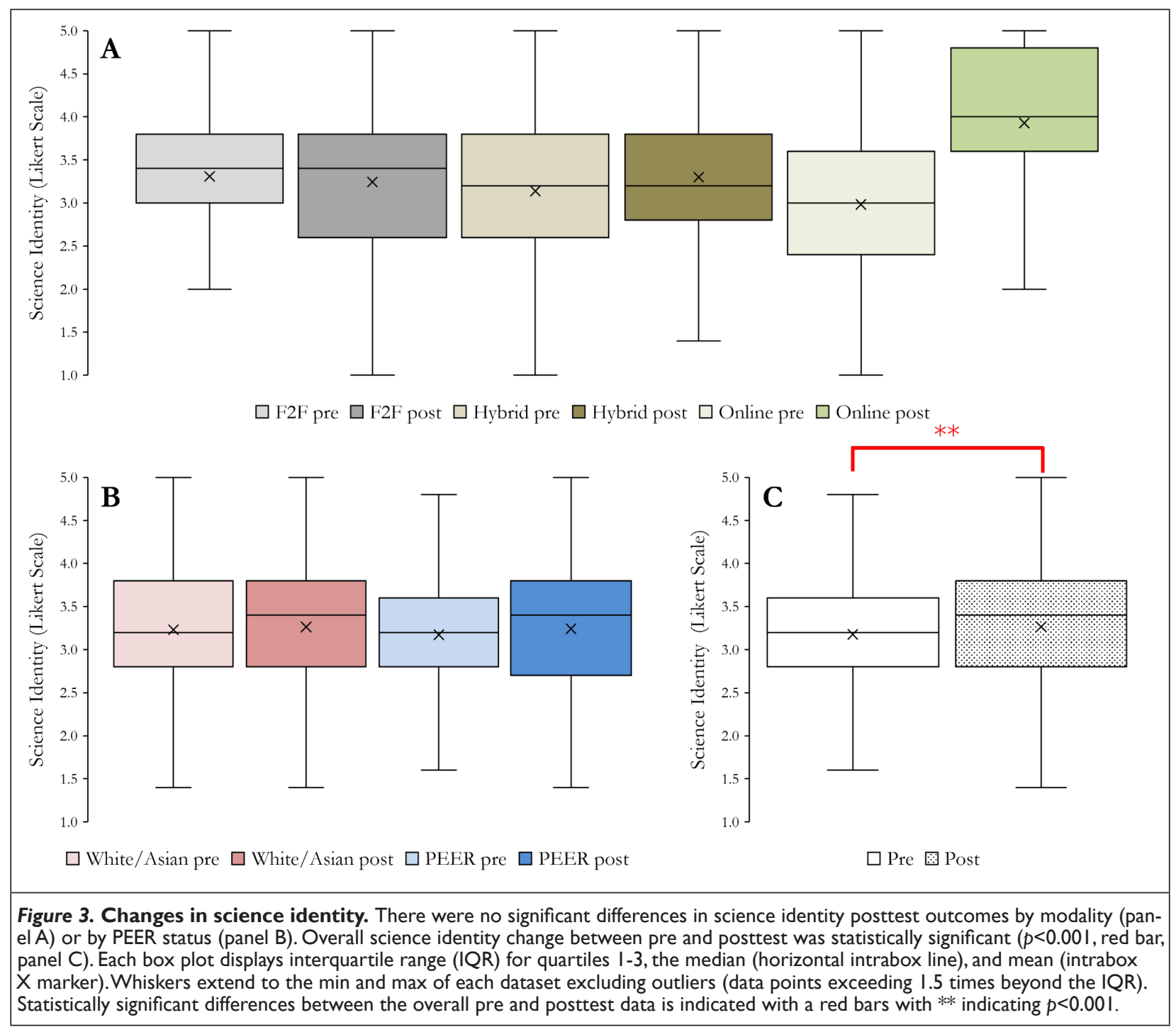


semester with the posttest questions included as part of the final practical exam which was taken during the laboratory period. In the hybrid and online modalities there were no practical exams so the posttest was graded for completion credit. Therefore, we expected that F2F students studied for the final practical exam and thus were better prepared to perform well on the posttest. It is of interest, however, that the knowledge gains in the hybrid group were significantly greater than the online group. Presumably, these groups had similar motivations, simply to complete the posttest without the added pressure of performance. This also removed the confounding variable of cheating which has been observed in other studies where the unsupervised posttest was given for a grade in those modalities (Hsu, 202I). Additionally, while the variances for the samples was similar for each statistical analysis done, differences in sample size lower the power of the study (Rusticus and Lovato, 20I4). Because of the lower power, any significant differences in learning outcomes and attitudinal trends were conservative. Considering the possible difference in motivation on the posttest, conservative estimates would help mitigate that limitation.

\section{LEARNING OUTCOMES}

F2F students scored significantly higher on analysis outcomes, but hybrid students matched the F2F gains in knowledge while outperforming the online students. (Figure I). This is inconsistent with most other research comparing F2F to online laboratory classes which indicates similar or better performance in online laboratories (Kuyatt and Baker, 20 I4; Mawn et al., 20I I;Al Musawi et al, 20I 5; Potkonjak et al., 20I 3; Zeynep and Alipasa, 20I3). Kuyatt and Baker (2014) surveyed student perceptions of learning after using an anatomy and physiology software program in F2F or online laboratory course. Like our study, this student population, were mostly allied health majors and a majority were female, however this study was conducted with a community college (two-year post-secondary schools) population. Students' perceptions of their own learning can be inflated when compared to objective tests of learning like were used in the Kyuatt and Baker study (Broud and Falchikov, 20 I5; Falchikov and Broud, 20I5). Mawn et al., (20II) studied the impact on data collection and analytic skills of one module in a course for non-science majors. Our students were mostly science and allied health majors (Table I) and our outcomes consisted of the learning and analytic outcomes from a semester course.

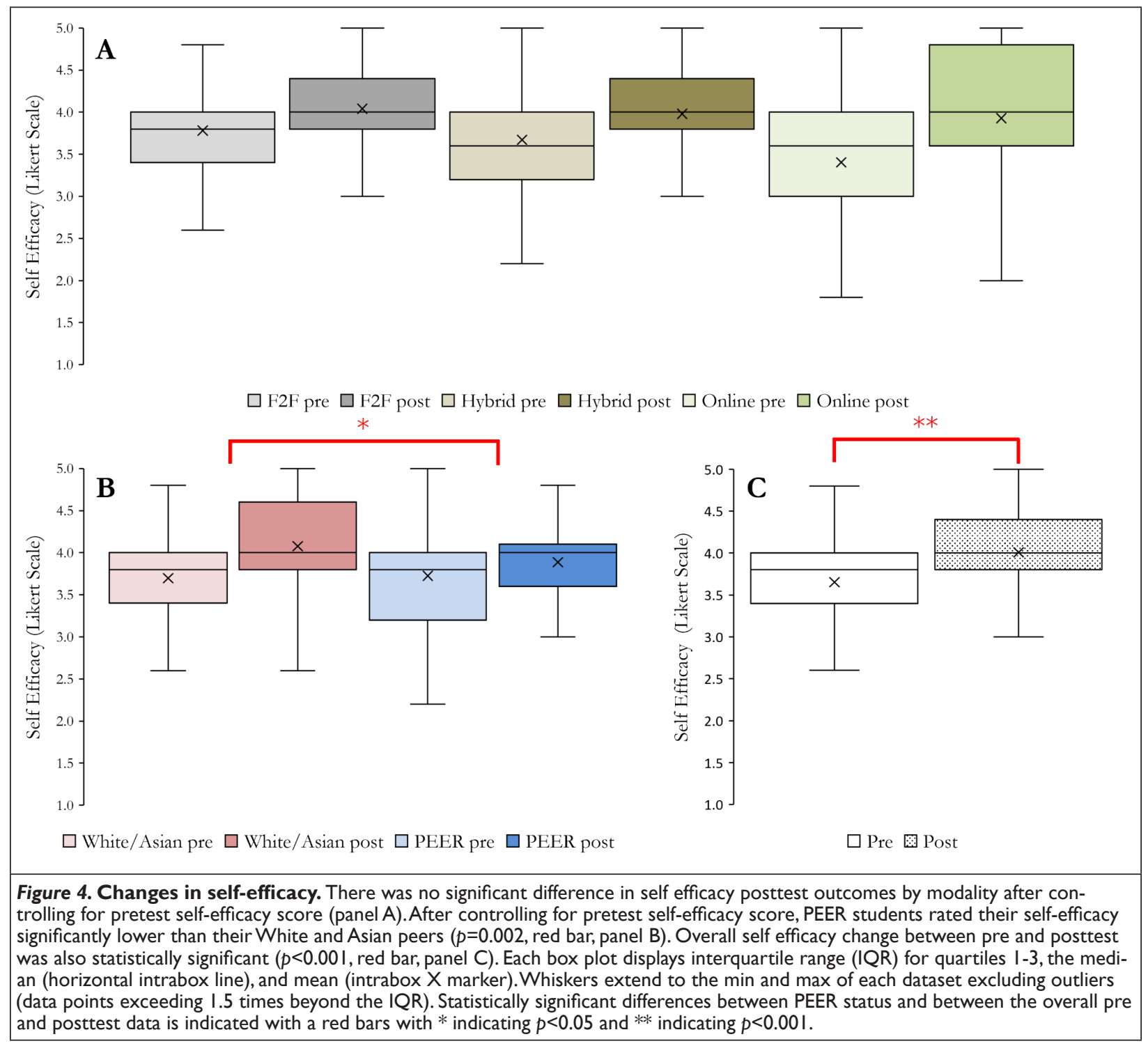


Our results also contrast with hybrid laboratory course studies (Olympiou \& Zacharia, 2012; Son et al., 2016). Son et al. found hybrid students had higher course grades and lower DWF rates than F2F and online students, but found no differences between the three modalities on knowledge of evolution or research methodology. However, this was a non-science majors course. In their hybrid condition, the students met F2F every other week compared to three times in the semester for our students. Olympiou and Zacharia (20I2) found higher learning outcomes for students in the hybrid condition, but they tested pretest and posttest immediately before and after one module (three experiments) during a physics laboratory course. Additionally all of the students met F2F, the comparison occurred between students using physical laboratory equipment, virtual laboratory equipment, or a mix of the two (hybrid). In the hybrid condition, assignment to virtual or physical laboratory equipment was based on which condition would provide the students the best environment to explore the phenomenon. Therefore, it is not surprising that the hybrid condition had the highest learning.

The prior studies were conducted with traditional not CURE laboratory courses. After optimizing a CURE for online, Genet (202I) found no differences in self-reported student learning gains compared to the F2F students in an introductory environmental science course at a community college. Our three modality CURE study seems to indicate that online students are disadvantaged in learning compared to $\mathrm{F} 2 \mathrm{~F}$ and hybrid students, while hybrid students did not learn to analyze the data as well as those in the F2F modality. However, we cannot discount the possible motivational impact for the F2F students who were completing this as part of an exam. It is also important to note here that the F2F and hybrid modalities were delivered in a typical I 5 week semester, whereas students completing the online course in the summer only had 5 weeks to process the material. These results highlight the need to conduct further studies that use objective tests of learning outcomes under the same testing conditions. Since the intention of CUREs is to replicate the benefits of mentored research, impact comparisons between modalities for persistence and science process skill metrics should be examined in future studies.

Our data suggests that CUREs are effective for a diverse student population since there were no significant differences between the knowledge and analysis gains of White/Asian and PEER students (Figure I). Knowledge gains for PEER students were similar across all modalities, which is consistent with the

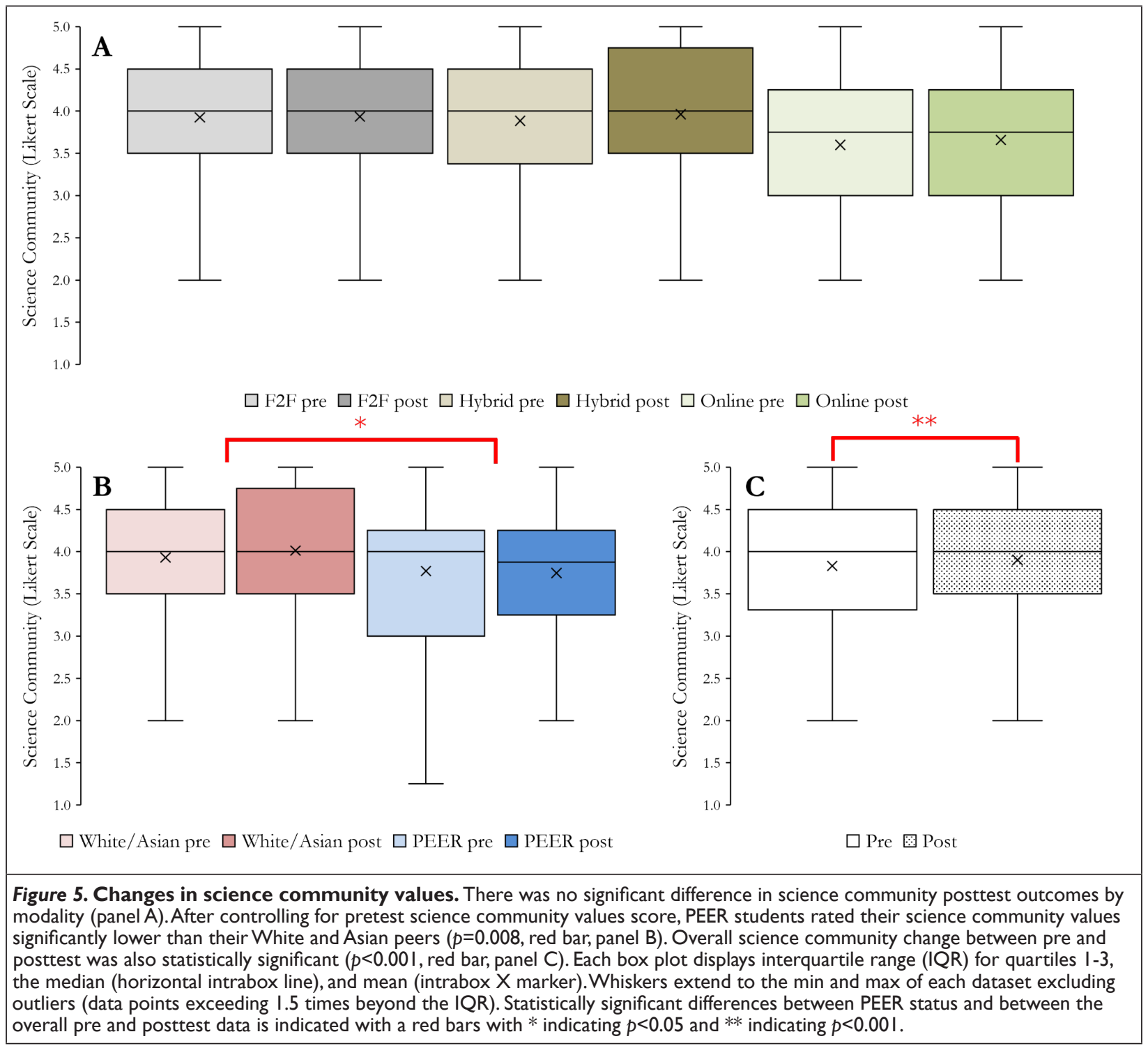


comparable increases in student lecture performance with a CURE laboratory component (Ing et al., 2020). This learning could also contribute to the increased six-year STEM graduation rate for all students seen by Rodenbusch et al. (2016) in their study of consecutive CURE student outcomes. This is encouraging and suggests that developing and implementing CUREs within online courses, especially at community colleges where there is a substantial population of at-risk students (Kuapp, 2012; Wladis et al., 20I5), may benefit the most students. There is a fascinating interaction between PEER status and modality for analysis questions, such that PEER students outperformed White/Asian students in the online modality, were similar in the hybrid modality, and had lower analysis learning gains for the F2F modality. This may be an artifact of the small sample size of the online condition or the difference in motivation in the online condition. However, in the hybrid condition the motivation for the posttest was similar to the online students, but still has a different pattern of achievement. As the first study to compare learning gains in CUREs across modalities, these results are both encouraging for the success of PEER students within an online CURE and suggest that more research in this area is urgently needed.

\section{ATTITUDINAL OUTCOMES}

Project ownership is the extent to which students feel that they have agency in their laboratory course (Hanauer and Dolan, 20I4). As measured by the PITS, it has two sub-scales that measure the extent to which students engage with the content and their emotional investment in the project (Hanauer et al., 2016). Project ownership is related to student's further success in science (Corwin et al., 2015; Hanauer, Frederick, Fotinakes, and Strobel, 2012; Hanauer et al., 2016). Students in CURE courses typically have higher feelings of project ownership than those in traditional laboratory courses (Cooper, Blattman, Hendrix, and Brownell, 2019; Hanauer and Dolan, 20I4; Hanauer et al., 2016) When developing the project ownership survey, Hanauer and Dolan compared project ownership across F2F classes in a widerange of institutions and a variety of class levels. In Cooper et al., F2F upper-division immunology students had higher level of content and emotional project ownership when analyzing the immune system of mutant mice strains compared to analyzing commonly studied mouse strains. Students in all three modalities and between PEER and White/Asian students had similar levels of project ownership (Figure 2), which were consistent with other CUREs (Cooper et al., 20I9; Hanauer et al., 20I7). This was a surprising result, since the students in the online modality were not able to complete the research project on the insect that they collected. All data after insect collection was provided to the students from an insect of the same Order. We expected that project ownership would be lower in the online modality However, project ownership is closely related to broad relevance of the CURE project (Cooper et al., 2019). In all three modalities, the relevance of the interaction between insects and Wolbachia impacts on human diseases are heavily emphasized which could account for this result.

Networking measures how often a student discusses their research with people outside of the laboratory classroom (Hanauer and Hatfull, 2015). This measure is important in predicting project ownership, intent to become a research scientist, and is higher in CUREs compared to traditional laboratories (Hanauer et al., 20I7; Hanauer et al., 20I6; Hanauer and Hatfull,
20I5). Students in the online modality had significantly lower networking than the other two modalities, however their project ownership was similar in all three modalities. The relationship between project ownership and networking was determined in a F2F condition (Hanauer and Hatfull, 20I5). Thus it is interesting that project ownership was not lower online while networking was. Online students were interacting with the material and the instructor mainly through written communication, whereas the F2F and hybrid modalities students had many opportunities to verbalize their thoughts with other students and the instructor. Using the language of science is important in constructing meaning (Osborne, 2002), and online delivery restricts students from practicing scientific terminology verbally. If students do not have an opportunity to practice verbally, they may be less inclined to talk with others outside of the course as indicated by the lower networking result. PEER students had significantly lower networking than White/Asian students. This is inconsistent with a nationwide study of a F2F introductory student CURE that surveys bacterial virus prevalence, which found no difference in networking between PEER and White/Asian students (Hanauer et al., 2017). Networking is a recent student outcome being measured in science laboratory settings (Hanauer and Hatfull, 20I5) and these results emphasize the need to explore networking in future studies.

Science identity is the student's sense of themselves as a scientist and it is important in student persistence in science and may be even more important for PEER students (Estrada, Hernandez, and Schultz, 2018; National Academies of Sciences and Medicine, 20I7; Robnett, Chemers, and Zurbriggen, 20I5). In the F2F modality, CUREs increase student's science identity compared to traditional laboratory courses (Esparza,Wagler, and Olimpo, 2020; Hanauer et al., 2017). Students in Esparza et al., were freshman science majors with less than 10 percent of their sample White. In this study, science identity significantly improves over the semester when considering all students (Figure $3 \mathrm{C}$ ) in the CURE. However, there is no significant difference between modalities. In this case, the impact of very different group sizes, which lowers the power, may be obscuring a significant difference between the online modality and the other two modalities (Figure $3 \mathrm{~A})$. There is a large visual difference between the online and F2F or hybrid modalities. Also, the modality statistic is close to the $p$ $<0.05$ cutoff $(F=2.580, p=0.077)$. These are encouraging results for the development of science identity in an online environment. There is also no significant difference by PEER status; this is consistent with Hanauer et al. (20I7), which examined science identity by PEER status in a large national CURE.

Self-efficacy is the belief in your ability to achieve a specific goal (Bandura, 1997). Self-efficacy is a key predictor in performance of a specific task and has been shown to be important in academic settings in teaching and learning (Chemers, Hu, and Garcia, 200 I; DeChenne, Koziol, Needham, and Enochs, 20I5; Pajares, 1996; Robnett et al., 2015). A review of CURE literature indicates a positive impact student's self-efficacy in functioning as a scientist compared to a traditional laboratory course (Corwin et al., 20I5). In a Hispanic serving institution, Shuster et al., (2019) also saw an increase in self-efficacy in an upper-division (mostly junior and senior students) biology CURE. In all modalities in this study, students' self-efficacy increased over the course of the semester (Figure 4), and there was no significant difference between modalities. This is a highly encouraging result because 
there is some evidence that students' self-efficacy drops during their introductory biology courses (Olimpo et al., 2016). However, the increase in PEER students' self-efficacy was significantly lower than the White/Asian students, which is inconsistent with the national sample from Hanauer et al. (2017) where there was no difference in science self-efficacy between these two groups of students. However, Hanauer et al. also did not see a significant difference in post-course self-efficacy between CUREs and traditional laboratory courses. Continued research on self-efficacy differences in CURES in all modalities and by student demographic status is important to understand this contradictory data.

Science community values are a student's agreement with values of the scientific community, such as the value and excitement of scientific research (Estrada, Woodcock, Hernandez, and Schultz, 20II). These values are predictive of self-efficacy and persistence in science (Chemers, Zurbriggen, Syed, Goza, and Bearman, 20I I; Estrada et al., 20l I). It is important to note that there is a correlation between some of the items in science identity and science community values which indicates that these are two closely related constructs (Hanauer et al., 2016). So it is not surprising that patterns in science community values are closely related to science identity; both increased significantly overall (Figure $5 \mathrm{C}$ ) but exhibited a slight drop in the F2F modality (Figures $3 \mathrm{~A}$ and $5 \mathrm{~A})$. However, there was no significant difference in the change of science community values among the three modalities. There was a significant difference in the science community values between White/Asian students and the PEER students (Figure 5B), with the White/Asian students increasing and the PEER students decreasing. Like science identity, science community values are in early exploration in CURE settings so there are few studies to compare. In their national CURE study, Hanauer et al. (20I7) found no differences in science community values by PEER status with a significantly higher score for students in CUREs compared to traditional laboratories.

\section{APPLICATIONS FOR TEACHING AND LEARNING}

The delivery of online laboratory courses has the potential to reduce departmental costs (Mgutshini, 20I3). Since there was no need to prepare reagents, no dedicated classroom space, and no need to devote personnel resources to the set-up/take down of different laboratory activities, one can assume there were financial savings for the department. However, these savings were, at least partially, offset by increased instructional costs to recruit faculty to deliver the online course in the summer. In addition, the department lost revenue in the form of laboratory course fees. The combination of lost revenue and increased instructional costs makes it difficult to determine if there were any financial savings for the department.

From the student's financial point of view, however, online laboratory courses may very well have reduced their financial burden. Online delivery meant there was no laboratory course fee and no need to travel to, or live on, campus. Given the likelihood that students experienced financial hardships due to the pandemic (Soria, Chirikov, and Jones-White, 2020; Soria, Horgos, Chrikov, and Jones-White, 2020; Soria, Roberts, Horgos, and Hallahan, 2020), the savings afforded to students may have made a positive financial impact.

During the transition to remote learning in 2020 , some of the biggest hurdles to learning included a lack of student motivation, learning difficulties in online formats, a lack of connection with classmates, and distracting home environments (Soria, Chirikov, et al., 2020). The barriers were more significant for PEER students. These students were more likely to lack access to technology or an appropriate study space. Moreover, PEER students were more likely to experience economic hardships in the form of reduced wages and family income, and unexpected living and technology expenses (Soria, Roberts, et al., 2020). Given the potential negative academic impacts that PEER students experience during the pandemic, and the resulting transition to online learning, the effect on student learning and attitudes seem to be minimalized in this course. Collectively there were no significant differences in either analytical or knowledge learning gains (Figure IB and E). However, when you look at learning gains by the different modality of delivery, PEER students did worse than White/Asian in the F2F class, but performed better in the online course (Figure IC). While PEER students were more likely to experience emotional, academic, and financial burdens with the transition to remote learning early in the pandemic (Soria, Roberts et al., 2020), these results suggest that PEER students have developed strategies to mitigate those hurdles. It would be of interest to determine what those strategies were.

This study presents encouraging results for the development of CUREs in the hybrid and online format. The development of a broadly relevant project is a cornerstone for CUREs and directly leads to students' feelings of ownership which are then related to other distal outcomes. For faculty interested in moving a currently established CURE to hybrid or online modalities, our evidence is that most of the outcomes from the already established CURE will translate well to the other modalities. As Genet (202I) did, experienced CURE faculty should, within a few iterative semesters, be able to replicate the student outcomes that are most important in their CURE to the online or hybrid modalities. Additionally, the online and hybrid modalities lend themselves particularly well to bioinformatics projects (e.g. Kickpatrick et al., 2019) which can be scaled up to accommodate more students since many programs and databases are available for free online.

This study adds to our growing understanding of the online and hybrid laboratory experience. It is the first study to perform an in-depth analysis of delivery of the same CURE curriculum at the same institution across three different teaching modalities. This is important as it removes several confounding variables from the study. This study suggests that CUREs can be adapted to the online or hybrid modality with minimal impacts on student outcomes compared to F2F laboratories. As the number of traditional aged university student population shrinks, online delivery provides a growth opportunity for departments. This is especially true for Biology departments where only I\% of the nation's biology programs offer an undergraduate online degree program (Wiley, 202I). While practical laboratory classes are seen as a major barrier to establishing online biology degree programs, the integration of CURE approaches to online laboratory courses could be a solution. Online degree programs have the added benefit of attracting students who have struggled to finish degrees in the F2F classroom. These students include highly transient populations such as active military and military affiliated students, as well as those who find it difficult to attend F2F classes, such as students with disabilities. We do not know what a post-pandemic campus will look like or how these changes will impact who physically comes to campuses, but we do know that online courses and 
degree programs will fuel future enrollment growth. It is imperative that we develop online laboratory experiences to meet the needs of this virtual future.

\section{ACKNOWLEDGEMENTS}

We would like to thank all of the students enrolled in this introductory biology course for allowing us the privilege of using their data for this study. We thank the Bordenstein Lab and the Wolbachia Project at Vanderbilt University for developing the original laboratory course that inspired this work and for continuing to provide Drosophila controls used by our F2F and hybrid modality students. We would also like to thank Sana Omar for her work on data collection and initial characterization of the Fall 2019 F2F modality in this study. This study was approved by the IRB of Georgia Southern University (HI 9002). This study was funded by the National Science Foundation (DUE- I 245077) and the Biology Department of Georgia Southern University.

\section{REFERENCES}

Al Musawi,A.,Ambusaidi,A., Al-Balushi, S., \& Al-Balushi, K. (20I5). Effectiveness of E-lab use in science teaching at the omani schools. TOJET:The Turkish Online Journal of Educational Technology, I 4, 45-52.

Asai, D. (2020). Excluded. Journal of microbiology \& biology education, 2 I (2). DOI: https://doi.org/ |0. I I28/jmbe.v2 Iil.207| .

Babinčáková, M., \& Bernard, P. (2020). Online exprimentation during COVID-19 secondary school closures: teaching methods and student perceptions. Journal of Chemical Education, 97(9), 3295-3300. doi: I0.102 I/acs.jchemed.0c00748

Ballen, C., Blum, J., Brownell, S., Herbert, S., Hewlett, J., Klein, J., McDonald, E., Monti, D., Nold, S., Siemmons, K. (2017). A call to develop coursebased undergraduate research experiences (CUREs) for nonmajors courses. CBE Life Science Education, 16, mr2. DOI: 10.1 187/cbe. I6-12-0352

Barber, P. H., Shapiro, C., Jacobs, M. S., Avilez, L., Brenner, K. I., Cabral, C., ... Levis-Fitzgerald, M. (202I). Disparities in remote learning faced by first-generation and underrepresented minority students during COVID-19: Insights and opportunities from a Remote Research Experience. Journal of Microbiology \& Biology Education, 22(I), 22.21.54. doi: I0. I I 28/jmbe.v22il 2457

Bandura, A. (1997). Self-efficacy:The exercise of control. New York, NY:W.H. Freeman and Company.

Bangera, G., \& Brownell, S. E. (20I4). Course-based undergraduate research experiences can make scientific research more inclusive. CBE-Life Sciences Education, I3(4), 602-606. doi: 10.1 I87/cbe. 14-06-0099

Barral, A. M., Makhluf, H., Soneral, P., \& Gasper, B. (20I4). Small World Initiative: crowdsourcing research of new antibiotics to enhance undergraduate biology teaching (6I8.4I). The FASEB Journal, 28(I Supplement), 618.64 I.

Biel, R., \& Brame, C. (20I6). Traditional versus online biology courses: connecting course design and student learning in an online setting. Journal of Microbiology \& Biology Education, 17(3): 417-422.

Bordenstein, S. R. (2007). Discover the Microbes Within!:The Wolbachia Project. ASM's Focus on Microbiology Education, I4(I), 4-5.
Boud, D., and Falchikov, N. (1989). Quantitative studies of student self-assessment in higher education: $\mathrm{A}$ critical analysis of findings. Higher Education, 18(5): 529-549.

Brownell, S. E., Hekmat-scafe, D. S., Singla, V., Seawell, P. C., Imam, J., Eddy, S. L., Stearns, T., Cyert, M. S. (20I5). A high-enrollment course-based undergraduate research experience improves student conceptions of scientific thinking and ability to interpret data. CBE-Life Sciences Education, I4(2), ar 21 .

Brownell, S. E., Kloser, M. J., Fukami, T., \& Shavelson, R. J. (20I3). Context matters: volunteer bias, small sample size, and the value of comparison groups in the assessment of research-based undergraduate introductory biology lab courses. Journal of Microbiology \& Biology Education:JMBE, I 4(2), I 76. doi: I 0. I I 28/jmbe.v| 4i2.609

Chang, M. J., Sharkness, J., Hurtado, S., \& Newman, C. B. (20I4). What matters in college for retaining aspiring scientists and engineers from underrepresented racial groups. Journal of Research in Science Teaching, 5 I (5), 555-580. doi: I 0. I 002/ tea. 21146

Chemers, M. M., Hu, L.-t., \& Garcia, B. F. (200I). Academic self-efficacy and first year college student performance and adjustment. Journal of Educational Psychology, 93(I), 55.

Chemers, M. M., Zubriggen, E. L., Syed, M., Goza, B. K., Bearman, S. (20II). The role of efficacy and identity in science career commitment among underrepresented minority students. Journal of Social Issues, 67(3): 469-49I.

Corwin, L. A., Graham, M. J., \& Dolan, E. L. (20I5). Modeling course-based undergraduate research experiences: an agenda for future research and evaluation. CBE Life Sci Educ, |4(I), es I. doi:I0.1 |87/cbe. |4-10-0167

Cooper, K. M., Blattman, J. N., Hendrix, T., \& Brownell, S. E. (2019). The impact of broadly relevant novel discoveries on student project ownership in a traditional lab course turned CURE. CBE-Life Sciences Education, I8(4), ar57.

DeChenne, S. E., Carew, J., \& Stains, M. (20I4). Published freshman lab exercises as indicators of level of awareness and adoption of instructional practices grounded in discipline-based education research. Journal of College Science Teaching, 43(6): 60-70.

DeChenne, S. E., Koziol, N., Needham, M., \& Enochs, L. (20I5). Modeling sources of teaching self-efficacy for science, technology, engineering, and mathematics graduate teaching assistants CBE-Life Sciences Education, I4(3), ar32. doi: I0. I I87/ cbe. I4-09-0153

Digest of Education Statistics. (2019). Table 325.20. Degrees in the biological and biomedical sciences conferred by postsecondary institutions, by level of degree and sex of student: Selected years, 195 I-52 through 2017-2018. National Center for Education Statistics. I 8https://nces.ed.gov/ programs/digest/dI9/tables/dt I9_325.20.asp (Accessed II-22-2I).

Doctor, E. L., Lehman, M., \& Korte, C. S. (202I). Implementing CUREs with Cookbook-Style Laboratory Exercises in In-Person, Online, and Hybrid Formats. Journal of Microbiology and Biology Education, 22(I). doi: I 0.I I 28/jmbe.v22il.2573 
Esparza, D.,Wagler,A. E., \& Olimpo, J.T. (2020). Characterization of instructor and student behaviors in CURE and nonCURE learning environments: Impacts on student motivation, science identity development, and perceptions of the laboratory experience. CBE-Life Sciences Education, 19(I), arl0.

Espinosa, L. (20I I). Pipelines and pathways:Women of color in undergraduate STEM majors and the college experiences that contribute to persistence. Harvard Educational Review, $8 I(2), 209-24 I$.

Estrada, M., Hernandez, P. R., \& Schultz, P.W. (2018). A longitudinal study of how quality mentorship and research experience integrate underrepresented minorities into STEM careers. CBE-Life Sciences Education, I 7(I), ar9.

Estrada, M.,Woodcock, A., Hernandez, P., Schultz, P. (20I I). Towards a model of social influence that explains minority student integration into the scientific community. Journal of Educational Psychology, I03(I): 206-222.

Falchikov, N. And Boud., D. (1989). Student self-assessment in higher education:A meta-analysis. Review of Educational Research, 59(4): 395-430.

Faulconer, E. K., \& Gruss, A. B. (2018). A review to weigh the pros and cons of online, remote, and distance science laboratory experiences. International Review of Research in Open and Distributed Learning, 19(2): I55-I68.

Fogg, L., Carlson-Sabelli, L., Carlson, K., \& Giddens, J. (2013). The perceived benefits of a virtual community: effects of learning style, race, ethnicity, and frequency of use on nursing students. Nursing Education Perspective, 34(6), 390-394. doi: $10.5480 / 1$ I-526. I

Genet Kristen, S. (202I). The CURE for introductory, large enrollment, and online courses. Scholarship and Practice of Undergraduate Research, 4(3), I3-2I.

Gin, L. E., Rowland, A. A., Steinwand, B., Bruno, J., \& Corwin, L. A. (20l8). Students Who Fail to Achieve Predefined Research Goals May Still Experience Many Positive Outcomes as a Result of CURE Participation. CBE-Life Sciences Education, I 7(4), ar57.

Hake, R. R. (1998). Interactive-engagement versus traditional method:A six-thousand-student survey of mechanics test data for introductory physics courses. American Journal of Physics, 66(I), 64-74.

Hanauer, D. I., \& Dolan, E. L. (20I4). The project ownership survey: measuring differences in scientific inquiry experiences. CBE-Life Sciences Education, I3(I), I49-I 58.

Hanauer, D. I., Frederick, J., Fotinakes, B., \& Strobel, S. A. (20I2). Linguistic analysis of project ownership for undergraduate research experiences. CBE-Life Sciences Education, I I (4), 378-385.

Hanauer, D. I., Graham, M. J., Betancur, L., Bobrownicki, A., Cresawn, S. G., Garlena, R. A., ... Russell, D. A. (2017). An inclusive research education Community (iREC): Impact of the SEA-PHAGES program on research outcomes and student learning. Proceedings of the National Academy of Sciences, I | 4(5I), | 353 I- | 3536.

Hanauer, D. I., Graham, M. J., \& Hatfull, G. F. (2016). A measure of college student persistence in the sciences (PITS). CBELife Sciences Education, I5(4), ar54.
Hanauer, D. I., \& Hatfull, G. (20I5). Measuring networking as an outcome variable in undergraduate research experiences. CBE-Life Sciences Education, I4(4), ar38.

Hsu, J. L. (202I). Promoting academic integrity and student learning in online biology courses. Journal of microbiology \& biology education, 22( I), ev22i2 I. 229l.

Hunnik, E. (20I5). Online college laboratory courses: Can they be done and will they affect graduation and retention rates? Higher Learning Research Communications, 5. doi:I0.18870/hlrc.v5i4.289

Ing, M., Burnette, J., Azzam, T.,Wessler, S., (2020). Participation in a course-based undergraduate research experience results in higher grades in the companion lecture course. Educational Researcher, DOI: 10.3102/00 I 3 I89X20968097.

Kemp, N. \& Grieve, R. (2014) Face-to-face or face-to-screen? Undergraduates' opinions and test performance in classroom vs. online learning. Frontiers in Psychology 5: I 278. doi. org/l 0.3389/fpsyg.2014.01278

Kirkpatrick, C., Schuchardt, A., Baltz, D., Cotner, S. (2019). Computer-based and bench-based undergraduate research experiences produce similar attitudinal outcomes. I. CBELife Sciences Education, I8(I): arl0.

Kuapp, R., (20I2). Online penalty: The impact of online instruction on the Latino-White achievement gap. Journal of Applied Research in the Community College, 19(2): 31 I.

Kuyatt, B. L. \& Baker, J. D. (20I4). Human anatomy software use in traditional and online anatomy laboratory classes: Student-perceived learning benefits. Journal of College Science Teaching, 43(5), I4- 15.

Lopatto, D. (2007). Undergraduate research experiences support science career decisions and active learning. CBE Life Sciences Education. 6: 297-306

Lemon, A., Bordenstein, S. R., \& Bordenstein, S. R. (2020). Discover the microbes within! The Wolbachia project: Citizen science and student-based discoveries for 15 years and counting. Genetics, 2 I 6(2), 263-268. doi: I 0. I 534/genetics. 120.303649

Martin, A., Rechs, A., Landerholdm, T., McDonald, K., (2021). Course-based undergraduate research experiences spanning two semesters of biology impact student self-efficacy but not future goals. Journal of College Science Teaching, 50(4): 33-47.

Mawn, M., Carrico, P., Charuk, K., Stote, K., \& Lawrence, B. (20I I). Hands-on and online: Scientific explorations through distance learning. Open Learning, 26, I35- | 46. doi: I $0.1080 / 026805$ I 3.2011 .567464

McCowan, L. J. (20I0). Blended courses:The best of online and traditional formats. American Society for Clinical Laboratory Science, 23(4): 205-20II.

Mgutshini, T. (20/3). Online or not? A comparison of students' experiences of an online and an on-campus class. Curationis, 36, I-7.

National Academies of Sciences, E., \& Medicine. (2017). Undergraduate research experiences for STEM students: Successes, challenges, and opportunities: National Academies Press. 
Olimpo, J., DeChenne-Peters, S. E., \& Fisher, G. R. (2016). Development and evaluation of the Tigriopus course-based undergraduate research experience: Impacts on students' content knowledge, attitudes, and motivation in a majors introductory biology course. CBE Life Sciences Education, December( I 5:ar72). doi: I0. I | 87/cbe. I5- I |-0228

Olympiou, G., \& Zacharia, Z. (20I2). Blending physical and virtual manipulatives:An effort to improve students' conceptual understanding through science laboratory experimentation. Science Education, 96, 21 -47. doi:10.1002/sce.20463

Osborne, J. (2002). Science without literacy:A ship without a sail? Cambridge Journal of Education, 32(2), 203-2I8.

Pajares, F. (1996). Self-efficacy beliefs in academic settings. Review of Educational Research, 66(4), 543-578. doi: $10.2307 / / 170653$

Paul, J., \& Jefferson, F. (2019). A comparative analysis of student performance in an online vs. face-to-face environmental science course from 2009 to 2016. Frontiers in Computer Science, I (7). doi: 10.3389/fcomp.2019.00007

Potkonjak, V., Jovanovic, K., Holland, O., \& Uhomoibhi, J. (20I3). Distance learning and skill acquisition in engineering sciences: Present state and prospects. Multicultural Education \& Technology Journal, 7, 64-88.

Rivera, J. (20I6). Science-based laboratory comprehension: an examination of effective practices within traditional, online and blended learning environments. Open Learning:The Journal of Open, Distance and e-Learning, 3I, 209 - 218.

Robnett, R. D., Chemers, M. M., \& Zurbriggen, E. L. (20I5). Longitudinal associations among undergraduates' research experience, self-efficacy, and identity. Journal of Research in Science Teaching, 52(6), 847-867.

Rodenbusch, S., Hernandez, P., Simmons, S., Dolan, E. (2016). Early engagement in course-based research increases graduation rates and completion of science, engineering, and mathematics degrees. CBE-Life Sciences Education, I5(2): ar20.

Russell, J., D’Costa,A.R., Runck, C., Barnes, D.W., Barrera,A.L., Hurst-Kennedy, J. Sudduth, E.B, Quinlan, E.L., Schlueter, M., Iskhakova, L.A., and Haining, R. (20I5). Bridging the undergraduate curriculum using an integrated course-embedded undergraduate research experience (ICURE). CBE Life Sciences Education. I4: I- 10.

Russell, S.H., Hancock, M.P., McCullough, J. (2007). Benefits of undergraduate research experiences. Science. 316(5824): 548-549.

Rusticus, S. \& Lovato, C. (20I4). Impact of sample size and variability on the power and Type I error rates of equivalence tests: A simulation study. Practical Assessment, Research \& Evaluation. Vol. 19, No. II. August.

Sadler,T. D., \& McKinney, L. (20I0). Scientific Research for Undergraduate Students:A Review of the Literature. Journal of College Science Teaching, 39(5), 43-49.

Shaffer, C. D., Alvarez, C., Bailey, C., Barnard, D., Bhalla, S., Chandrasekaran, C., ... Du, C. (20I0). The Genomics Education Partnership: successful integration of research into laboratory classes at a diverse group of undergraduate institutions. CBE-Life Sciences Education, 9(I), 55-69.
Shuster, M. I., Curtiss, J.,Wright, T. F., Champion, C., Sharifi, M., \& Bosland, J. (2019). Implementing and evaluating a coursebased undergraduate research experience (CURE) at a Hispanic-serving institution. Interdisciplinary Journal of Problem-Based Learning, 13(2).

Sommers, A. S., Miller,A.W., Gift, A. D., Richter-Egger, D. L., Darr, J.P., \& Cutucache, C. E. (202I). CURE Disrupted! Takeaways from a CURE without a Wet-Lab Experience. Journal of Chemical Education, 98(2), 357-367. doi: I0.102 I/acs. jchemed.0c01214

Son, J., Narguizian, P., Beltz, D., and Desharnais, R. (2016). Comparing Physical,Virtual, and Hybrid Flipped Labs for General Education Biology. Online Learning 20 (3): 228-243.

Soria, K. M., Chirikov, I., \& Jones-White, D. (2020). The obstacles to remote learning for undergraduate, graduate, and professional students. SERU Consortium, University of California - Berkeley and University of Minnesota.

Soria, K.M., Horgos, B., Chirikov, I., \& Jones-White, D. (2020). First-generation students' experiences during the COVID-19 pandemic. SERU Consortium, University of California-Berkeley and University of Minnesota.

Soria, K. M., Roberts, B.J., Horgos, B., \& Hallahan, K. (2020). The experiences of undergraduate students during the COVID-19 pandemic: Disparities by race and ethnicity. SERU Consortium, University of California - Berkeley and University of Minnesota.

Spell, R. M., Guinan, J. A., Miller, K. R., \& Beck, C.W. (20I4). Redefining authentic research experiences in introductory biology laboratories and barriers to their implementation. CBE-Life Sciences Education, I3(1), I02-I I0. doi: I0.1 I87/ cbe.13-08-0169

Trpkovska, M. A. (20I I, 27-30 June 20 I I). A study of student perceptions on blended and online learning over traditional classroom instruction at South East European University. Paper presented at the Proceedings of the ITI 20 I I, 33rd International Conference on Information Technology Interfaces.

US Census Data (2020). Accessed at https://datausa.io/profile/ geo/savannah-ga/\#category_heritage on November, 22 2021.

Waldrop, M. (20 I 3). Education online:The virtual lab. Nature, 499, 268-270. doi: 10.1038/499268a

Wei, C. A., \& Woodin, T. (20I I). Undergraduate research experiences in biology: alternatives to the apprenticeship model. CBE-Life Sciences Education, I0(2), I23-I31. doi: I0.1 I87/ cbe. I I-03-0028

Wiley Education Services. (202I). The state of the education market:Trends and insights in key bachelor's disciplines. Wiley: Louisville, KY

Wladis, C., Conway, K. M., \& Hachey, A. C. (20I5). The online STEM classroom-who succeeds? An exploration of the impact of ethnicity, gender, and non-traditional student characteristics in the community college context. Community College Review, 43(2), I42- 164. doi:I0.II77/009|552II557|729

Zeynep, T., \& Alipasa,A. (20I3). Effect of a virtual chemistry laboratory on students' achievement. Journal of Educational Technology \& Society, I 6(I), I59- 170. 


\section{APPENDIX - LEARNING TEST}

Analysis Questions: 5, 6, 7, 8, 9, 11, 17

Knowledge Questions: 1, 2, 3, 4, 10, 12, 13, 14, 15, 16, 18, 19, 20

I. Why should a scientific article be peer-reviewed before it is published in a scientific journal? To ensure that:

a. peers within the scientific community receive the information within the article

b. the article contains a complete summary of the concepts in an area of science

c. the authors of the article have engaged in a comprehensive and thoughtful process of experimentation that has yielded reliable results

d. the leaders within a field of science are the first to receive the information within the article

e. the procedures, data, and conclusions within the article are correct

2. Which of the following is the main purpose of a research article in a scientific journal?

a. to communicate data that are new to a field of research

b. to explain research findings to the general public

c. to focus on the thoughts, feelings, and ethical concerns that new scientific data and conclusions generate

d. to present a scientist's critique of another scientist's data and conclusions

e. to summarize related findings from many researchers in a field of science

3. Which of the following best describes the scientific process as it is truly practiced?

a. a complex process rigidly followed by experienced scientists to discover new information

b. a flexible process that includes one or more of a group of activities, each of which is completed as necessary to discover new information

c. a hypothesis is tested to discover new information

d. a series of steps that are completed in a specific order to discover new information

4. Which of the following best describes a scientific hypothesis?

a. It can and should be proven correct according to experimental results.

b. It describes a feeling or belief of a scientist.

c. It is a testable statement that answers a scientific question and should be accepted or rejected according to experimental results.

d. It is the foundation for all types of scientific research.

e. It may or may not be proven correct according to experimental results.

5. "The local Hemipteran population exhibits a high prevalence of Wolbachia infection." The previous statement is which of the following?
a. a hypothesis
b. a prediction
c. a question
d. an observation

6. The standard curve depicted to the right was generated using the indicated protein standards. The absorbance of a solution with an unknown concentration of pro. tein was determined to be I.2 What is the approximate concen. tration of protein in this solution?

a. $\quad 4.3 \mathrm{mg} / \mathrm{mL}$ of protein

b. $\quad 3.5 \mathrm{mg} / \mathrm{mL}$ of protein

c. $\quad 0.4 \mathrm{mg} / \mathrm{mL}$ of protein

d. $\quad 0.3 \mathrm{mg} / \mathrm{mL}$ of protein

e. $\quad 0.2 \mathrm{mg} / \mathrm{mL}$ of protein

\section{Calculators are not permitted.}

\begin{tabular}{|c|}
\hline $\begin{array}{c}\text { Protein standard } \\
\text { concentrations (in } \\
\mathrm{mg} / \mathrm{mL})\end{array}$ \\
\hline 0.20 \\
\hline 0.40 \\
\hline 0.60 \\
\hline 0.80 \\
\hline 1.00 \\
\hline
\end{tabular}

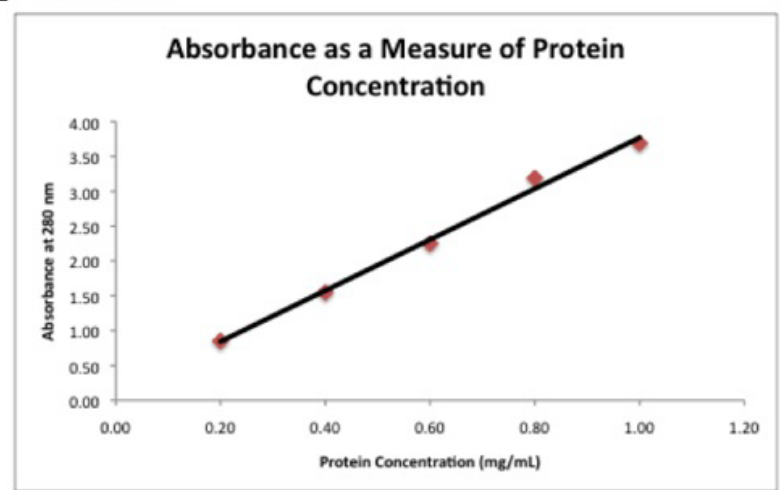


7. You determine that an unknown protein solution has an absorbance (O.D.) of I.5. How would you use this data and the equation of a line (e.g., $y=3.5 x+0.15)$ to determine the protein concentration of your unknown solution?

a. Insert the absorbance value for $x$, the independent variable, and solve for $y$

b. Insert the absorbance value for $y$, the independent variable, and solve for $x$

c. Insert the absorbance value for $x$, the dependent variable, and solve for $y$

d. Insert the absorbance value for $y$, the dependent variable, and solve for $x$

\section{Use the data below to answer the next question (8):}

Four researchers were asked to repeatedly pipette $5.0 \mathrm{~mL}$ of liquid in order to check the accuracy and precision of their pipetting. The table below represents the compiled results for each researcher. Using this information, answer the following question.

\begin{tabular}{|l|l|l|}
\hline Researcher & True value \% error & Average pipetted volume Standard Deviation \\
\hline Clark & $5.0 \mathrm{~mL}+/-20.5 \%$ & $5.00 \mathrm{~mL}+/-0.85$ \\
\hline Miguel & $5.0 \mathrm{~mL} /-6.3 \%$ & $5.01 \mathrm{~mL} /-0.10$ \\
\hline Shondra & $5.0 \mathrm{~mL}+/-11.7 \%$ & $4.86 \mathrm{~mL}+/-0.07$ \\
\hline Sierra & $5.0 \mathrm{~mL}+/-24.7 \%$ & $6.04 \mathrm{~mL}+/-0.53$ \\
\hline
\end{tabular}

8. Which researcher exhibited the most precise pipetting?
a. Clark
b. Miguel
c. Shondra
d. Sierra

9. Which graph best describes the follow. ing statement? "As the amount of DNA increases, the absorbance increases."
a. A
b. B
c. C
d. D
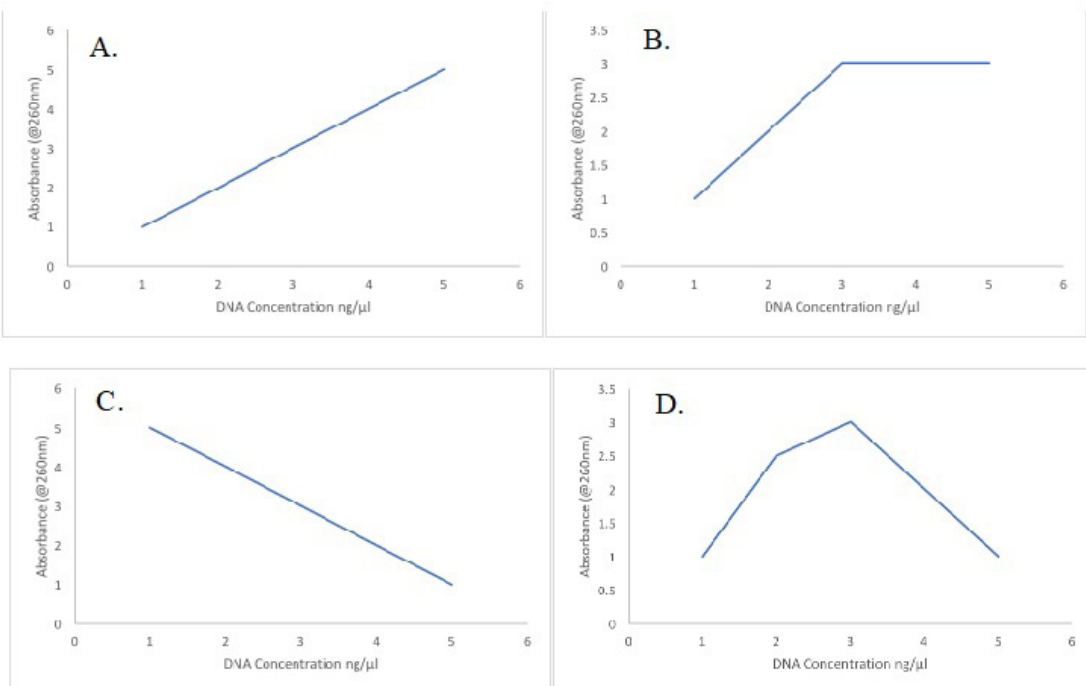

10. DNA extraction is a technique commonly used in molecular biology labs. Which of the following describes one application of DNA extraction?

a. to determine the location of DNA within a cell

b. to sequence the DNA to determine the identity of an organism

c. to study the chemical properties of the amino acids that make up its primary structure

d. to understand the structure of the nucleus of a cell 
II. The results of several DNA extractions are shown in the table below. Assume that all of the extractions resulted in the same volume of DNA. Which extraction provided the most DNA?
a. Sample I
b. Sample 2
c. Sample 3
d. Sample 4
e. Sample 5

\begin{tabular}{|c|c|c|c|}
\hline Sample \# & $\mathbf{A}_{260}$ & $\mathbf{A}_{280}$ & $\mathbf{A}_{260} / \mathbf{A}_{280}$ \\
\hline $\mathrm{I}$ & $\mathrm{I}$ & 2 & 0.5 \\
\hline 2 & $\mathrm{I}$ & $\mathrm{I} .5$ & 0.67 \\
\hline 3 & $\mathrm{I} .5$ & $\mathrm{I} .5$ & $\mathrm{I}$ \\
\hline 4 & 2 & $\mathrm{I} .5$ & $\mathrm{I} .33$ \\
\hline 5 & $\mathrm{I}$ & 0.5 & 2 \\
\hline
\end{tabular}

12. PCR is a molecular biology technique that amplifies its target(s) very specifically. Which PCR ingredient specifically targets the DNA of interest?
a. the buffer
b. the template of genomic DNA
c. the magnesium
d. the primers
e. the Taq polymerase

13. To which cellular process is PCR most similar?
a. DNA repair
b. DNA replication
c. Protein synthesis
d. Transcription
e. Translation

14. PCR is considered to be a very sensitive technique because it can detect trace amounts of DNA in a sample. Which of the following aspects of PCR generates this sensitivity?
a. the high fidelity of the DNA polymerase
b. the numerous rounds of melting, annealing, and extension
c. the proper use of control DNA
d. the thermostability of the DNA polymerase
e. the use of RNA primers

15. Suppose that you worked in a laboratory designing a PCR test to detect the presence of West Nile Virus in a patient's sample. Your supervisor says that you need to include a control that verifies that the reactions have not been contaminated with DNA from the environment or from another sample. Which of the following would best serve to test for contamination?
a. a reaction that contains all of the reaction components except template DNA
b. a reaction that contains DNA of the West Nile Virus
c. a reaction that contains extra enzyme
d. a reaction that contains primers that are specific for human DNA
e. a reaction that contains the patient's DNA

16. Electrophoresis can be used to separate based on their
a. carbohydrates; polarity.
b. lipids; structure.
c. membranes; thickness.
d. nucleic acids; size.
e. proteins; number of polypeptides.

17. In the figure of a gel to the right, which lane has the largest DNA product?
a. A
b. B
c. C
d. D
e. E

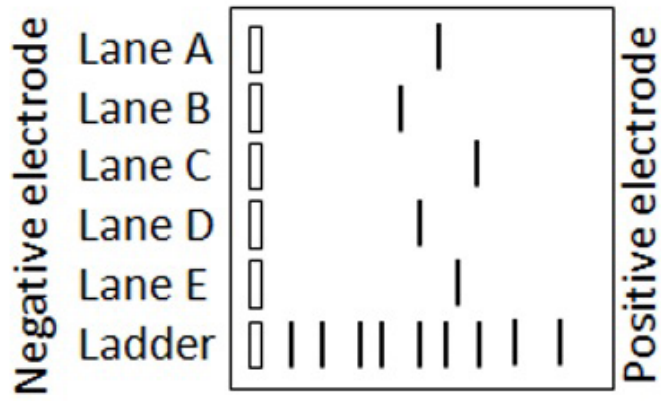


18. During the initiation of transcription, the enzyme binds to the and transcribes the template strand, shown here as the

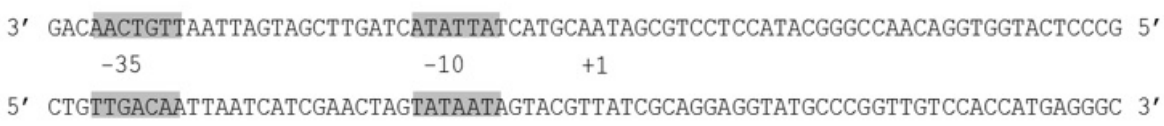
a. DNA polymerase / + I site / bottom strand
b. DNA polymerase / promoter / bottom strand
c. DNA polymerase / ribosomal binding site / bottom strand
d. RNA polymerase / + I site / top strand
e. RNA polymerase / promoter / top strand

19. Suppose you're analyzing an ORF encoding a polypeptide that contains 18 amino acids. This ORF would then contain sense codons.
a. 3
b. 6
c. 9
d. 18
e. 54

20. Imagine you are annotating a recently sequenced 100,000 base pair section of a bacterial genome. You have identified a region of DNA that likely encodes for a protein. Which of the following would be the best way to predict the type of protein that this gene encodes for?

a. analyze the sequence using BLAST

b. analyze the sequence using the ORF finder

c. look at the sequence by eye to find both start and stop codons

d. look at the sequence by eye to find start codons 